\title{
COMPARISON OF INVESTIGATION METHODS AT A KARST SITE
}

Michael J. Byle, P.E.

Tetra Tech, Inc.

One Oxford Valley, Suite 200

Langhorne, PA, USA, michael.byle@tetratech.com

\begin{abstract}
Over a period of several years, multiple investigation methods were used to assess conditions within the area of a stormwater infiltration basin. The initial investigation was a conventional geotechnical study using auger borings. This was supplemented with conductivity based electrical methods of geophysics. No adverse risk was identified in the initial investigation, however sometime later sinkholes formed and additional investigations were undertaken. The new investigation added seismic and spontaneous potential geophysics, as well as, rock cores with borehole televiewer. Subsequently, the area was excavated to expose the top of rock surface. Comparison of both the initial and additional investigations to the exposed conditions show limitations of the methods used. This paper presents a comparison of the results by the different methods and the actual conditions exposed in excavations as well as the effectiveness of each method in representation of subsurface features.
\end{abstract}

\section{Introduction}

In areas of carbonate bedrock, the potential sinkholes is a factor to be considered for development. Geophysical and geotechnical testing are often performed in addition to conventional geotechnical borings in efforts to evaluate the presence and nature of subsurface karst features for geotechnical engineering purposes. Numerous geophysical methods are often used for investigation of karst with varying degrees of success. These most commonly consist of electromagnetic and seismic methods, though other methods such as gravity survey also have application.

The subject of this paper is a confidential location within an area of carbonate geology with a regional history of sinkhole activity. Investigations were conducted using electromagnetic methods of geophysics together with soil borings to collect information for design of a stormwater infiltration basin. The site developed sinkholes shortly after the basin was constructed and additional investigations were made.

The general area was known to be carbonate geology with dipping beds. There were sinkhole features mapped within areas nearby the project site, but no features had been recorded within the project boundary. Accordingly, some limited investigation was planned by the designer to assess the sinkhole potential. Ground water is deep at the site, generally below $50 \mathrm{ft}$ depth

\section{Initial Geophysical Methods}

A number of geophysical methods are available for geotechnical subsurface characterization as listed in ASTM D6429 and USACE EM 1110-1-1802. While these documents are helpful, they do not specifically address karst. The initial investigation of the site included two different geophysical methods of investigation. These included terrain conductivity (TC) and capacitively-coupled resistivity (CCR). The intent was for the TC survey, completed using a Geonics EM-31, to assess near surface conditions within the upper $15-20 \mathrm{ft}$, and for the CCR survey, completed using a Geometrics OhmMapper, to assess deeper conditions 30 to 50 feet deep. The initial investigation included a few shallow borings, typically 4-6+/- feet deep to evaluate soil properties for infiltration.

\section{Terrain Conductivity}

The TC method is based on inducing a current in the subsurface by applying an electromagnetic field from a source coil. The induced current produces a secondary electromagnetic field through a second coil. The Geonics EM-31 has a fixed coil spacing of $10 \mathrm{ft}$. At this spacing the effective depth of investigation is expected to be about 20 feet, depending upon conditions. The device can measure ground conductivity in quadrature-phase 
and magnetic susceptibility through in-phase measurements. The quadrature phase is typically most useful in karst investigations for measuring variations in the ground conductivity associated with differences in material conductivity between areas of unweathered rock versus soils and voids associated with karst. The method is sensitive to the presence of conductive materials at or above the surface near the area of testing and the presence/absence of groundwater which will affect conductivity of soils, voids, and rock.

\section{Capacitively-Coupled Resistivity}

Resistivity generally measures the resistance of the ground to an applied voltage between electrodes inserted in the ground. The CCR method is intended to achieve roughly the same result, but uses an ungrounded dipole transmitter and receiver, to induce and measure the current similar to the TC method. Its advantage over conventional resistivity testing is the elimination of the need to install electrodes, which can be time consuming and problematic in paved areas. Through CCR, the AC current coupled into the earth by the transmitter and measured as a voltage at the receiver which is proportional to the resistivity of the earth between the dipoles. Apparent resistivity is calculated using the appropriate geometric factor for the capacitively-coupled antenna array. The spacing between the transmitter and receiver are varied to produce measurements reflective of different depths. For this investigation, the resistivity from CCR was reported in the inverse as conductivity for ease of comparison with the TC data.

\section{Initial Findings}

The initial TC investigation indicated generally uniform conditions with no abrupt changes in conductivity that would indicate karst anomalies. The conductivity was elevated around the site perimeter and along an access way through the site (magenta areas in Figure 1).

The elevated conductivity appears to have been related to interference from a wire fence on the site perimeter and the presence of slag aggregate in the access roadway. The deeper conditions at the $30 \mathrm{ft}$ target depth reflected by the CCR method showed generally similar conditions with less apparent influence of surface metallic features around the perimeter of the site (Figure 2). The CCR with antenna array set for $50 \mathrm{ft}$ target depth likewise showed



Figure 1. Initial Terrain Conductivity Results. Note the presence of metal detected along roadway and perimeter

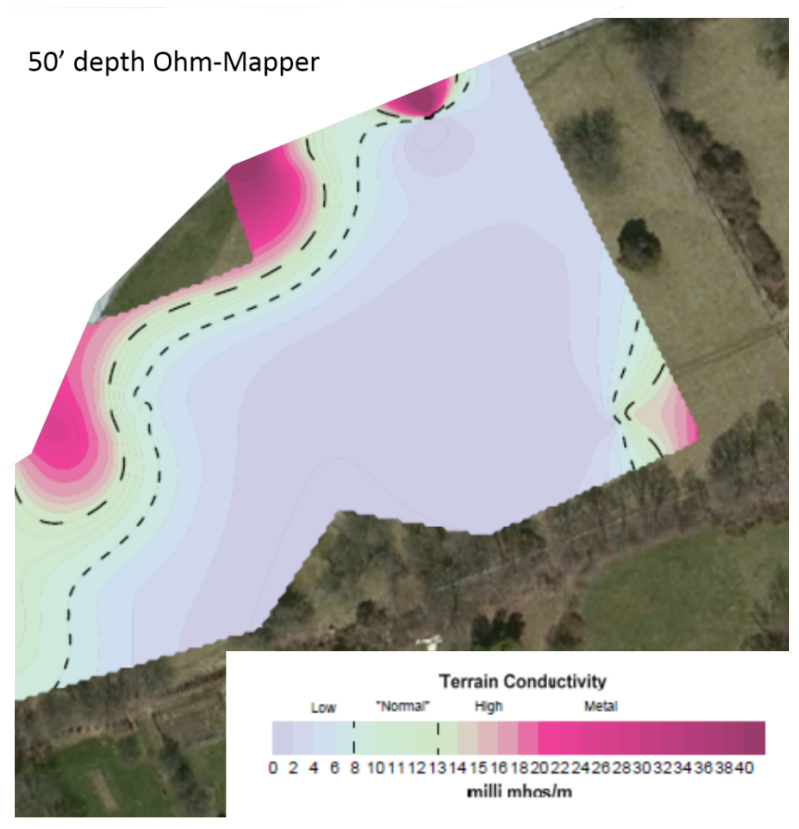

Figure 2. Capacitively-Coupled Resistivity; 35' target depth, plotted as conductivity.

fairly little variation and no evidence of discreet karst features within the center of the site but indicated some higher conductivity around the site perimeter (Figure 3 ). The borings conducted to depths of 4 to $6 \mathrm{ft}$ encountered only soils consisting sandy silty clay. Based on the absence of identified karst features by the geophysics and soil sampling, the risk of sinkhole formation was consid- 


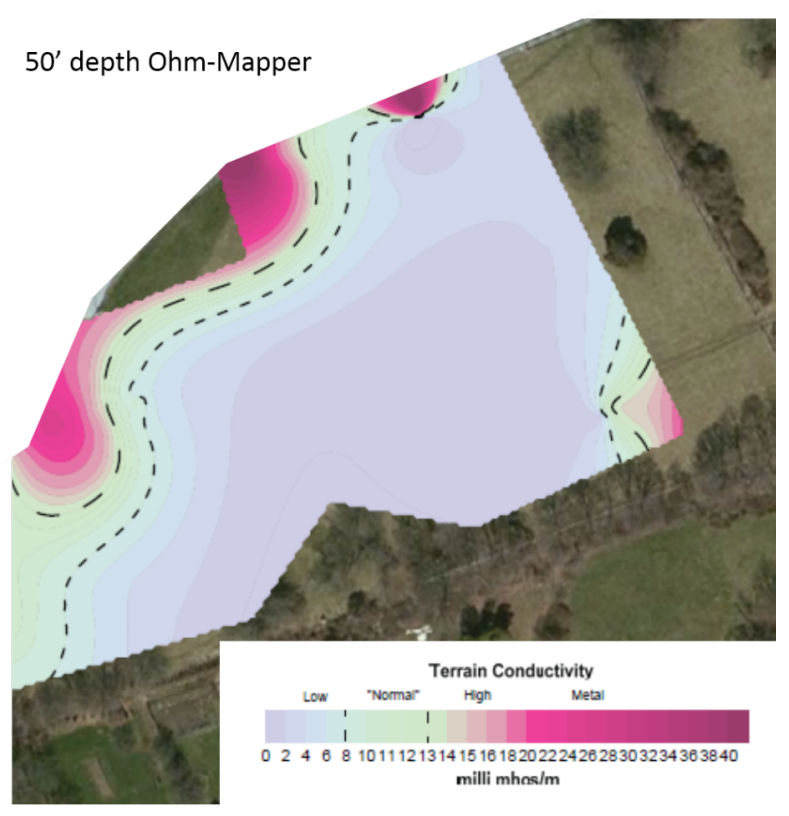

Figure 3. Capacitively-Coupled Resistivity; 50' target depth, plotted as conductivity.

ered low by the designer and the site was developed as an infiltration basin.

\section{Post Construction Sinkholes}

With the addition of surface water infiltration, the previously unidentified karst conditions revealed themselves. Sinkholes opened within the basin shortly after construction. The subsidence occurred within the southern portion of the basin shortly after the basin was put into service. In an area approximately 50 feet in diameter, two collapses occurred after a large precipitation event (Figure 4).

\section{Second Investigation}

As a result of the sinkhole development, additional investigation was conducted with the intent to evaluate the collapse areas and assess likelihood for occurrence of additional sinkholes at other locations within the basin. The additional investigation included Seismic Refraction (SR) and Spontaneous Potential (SP) geophysics, geotechnical borings with rock core and televiewer survey, and test excavations.

\section{Seismic Refraction}

Seismic Refraction is a surface geophysical method whereby a seismic pulse is induced on the ground surface and the refracted seismic pulse is received by seismic receivers (geophones) spaced along a line on the ground surface. The timing of first arrival of the seismic pulse is plotted against distance to identify changes in velocity attributed to refraction from deeper layers of higher velocity. The results of multiple tests are combined and assessed tomographically to develop seismic velocity profiles for each test line. The lines are plotted together to assess the iso-velocity topography as contour maps that indicate the depth to a specific velocity layer.

\section{Spontaneous Potential}

Spontaneous potential measures the naturally occurring voltage in the ground between electrodes inserted into the soil surface. These SP surveys use high-impedance digital microvolt meters to measure naturally-occurring electrical potential differences at the surface of the Earth. Small natural electrical potential differences occur between almost any two points on the ground surface. These natural potential differences are the result of fluid

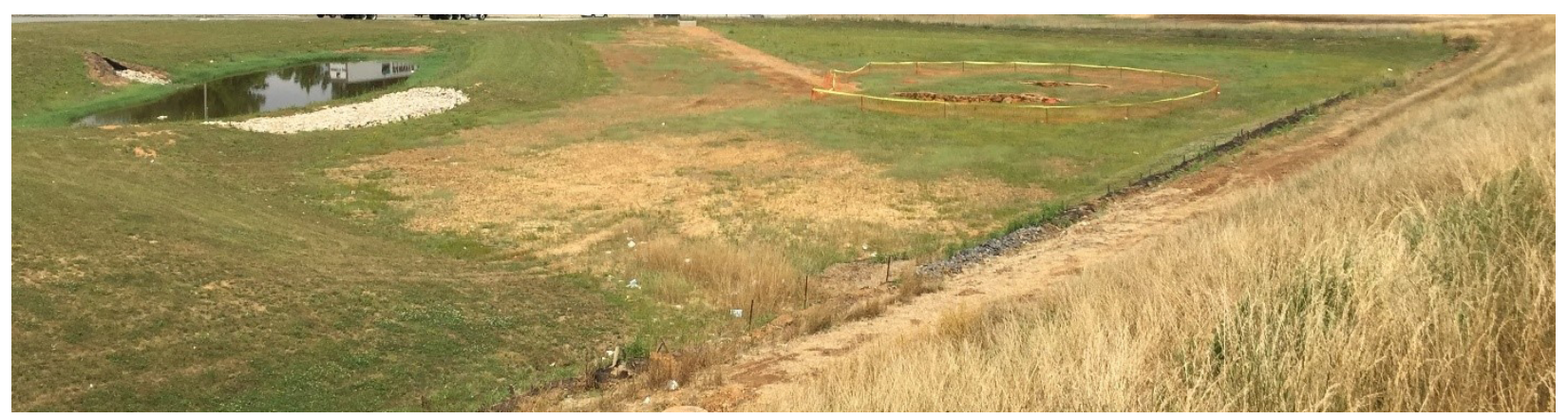

Figure 4. View of Basin Showing Sinkhole Locations 
moving through a permeable medium that gives rise to voltages known as streaming potentials. Downward infiltration often result in SP negative readings, while high positive values often surround these because of electrostatic attraction surrounding the negative areas.

Wightman et al. (2003) indicate SP to be a useful method in karst conditions. This is because flow is concentrated in karst features generating spontaneous electrical potential which can be measured at the surface. For this study, SP readings were collected, using an Advanced GeoSciences, Inc. Sting R-1 meter and non-polarizing ceramic electrodes, at grid stations surrounding the zone of subsidence. The reference potential electrode is placed outside the area of measurement.

\section{Borings and Televiewer}

Borings were conducted with a typical soil boring rig using hollow-stem augers through the soil overburden to the top of rock. Standard split-spoon samples were collected to assess soil consistency and type. The hollow stem auger was used as a casing and HQ-size diamond core was taken a minimum of $10 \mathrm{ft}$ into rock and up to a depth of $40 \mathrm{ft}$.

The Televiewer is a device that uses optical and acoustic survey methods to record conditions on the walls of the borehole. The device is oriented and lowered into the hole and it records conditions in 360 degrees around the perimeter of the borehole continuously to the top of the cored hole. It is only useable where the rock has sufficient integrity to stand open.

\section{Test Excavations}

Test excavations were conducted over the area of the sinkholes to assess conditions and verification of the geophysical investigation.

\section{Results of Second Investigation}

The second investigation revealed greater variability than was indicated in the initial investigation. The uppermost layer of soil was designated for compression wave (P-wave) velocities from 300 to 1,400 meters per second (mps)(1,000 to 4,500 fps), a range typical for unconsolidated silt and clay soils. The zone below that between 1,400 to $3,000 \mathrm{mps}(4,500$ to $10,000 \mathrm{fps})$ was interpreted as an epikarst zone. Sound rock, the deepest layer, has velocities greater than $3000 \mathrm{mps}$ (10,000 fps) (Carmichael, R. S., 1989). For the purposes of assessment, the inferred bedrock was taken at seismic velocity of $2100 \mathrm{mps}$ (7,000 fps). Area plots generated topographic assessment of the interpreted top of epikarst and top of sound rock are shown in Figures 5.

Three borings were drilled to characterize the materials and to be used to ground-truth the geophysics. The boring locations and elevations are shown on the epikarst

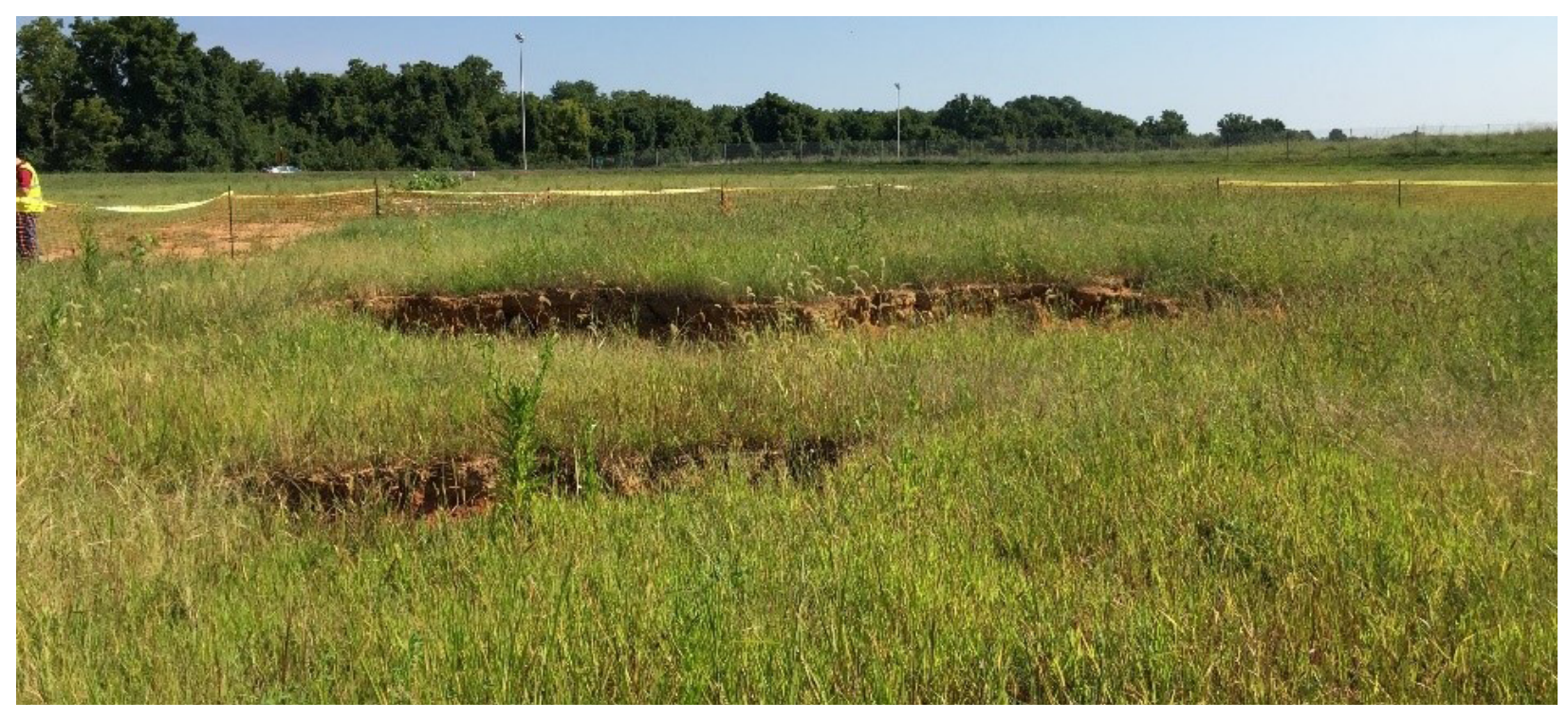

Figure 5. Post Construction Sinkholes 
and inferred bedrock maps in Figure 5. As can be seen, the top of rock elevation from the borings is in excellent agreement with the inferred rock for the SR survey generally falls within the range between inferred top of karst and inferred top of rock..

The SP testing produced an interesting pattern of values that can be correlated to the location of infiltration zones within the site that is expected to correlate to locations of active karst pathways for seepage. Figure 6 illustrates the results of the SP tests. The zones of downward seepage tend to generally coincide with areas of deeper indicated bedrock/epikarst north of the sinkhole area. Sebsequent to this study, additional sinkholes opened directly over most of these downflow areas.

While the SP and SR testing provide an improved picture over the TC and CCR testing, concerns remain about the localized variability that would not be detected by these methods. Resolution of these methods is limited by the spacing between survey lines, irregularity and depth of the rock surface and nature of karst features. Where karst features consist of discrete openings or conduits through the rock, SR will tend to miss these details. The SP would tend to identify features where water flow is present but may not identify all features.
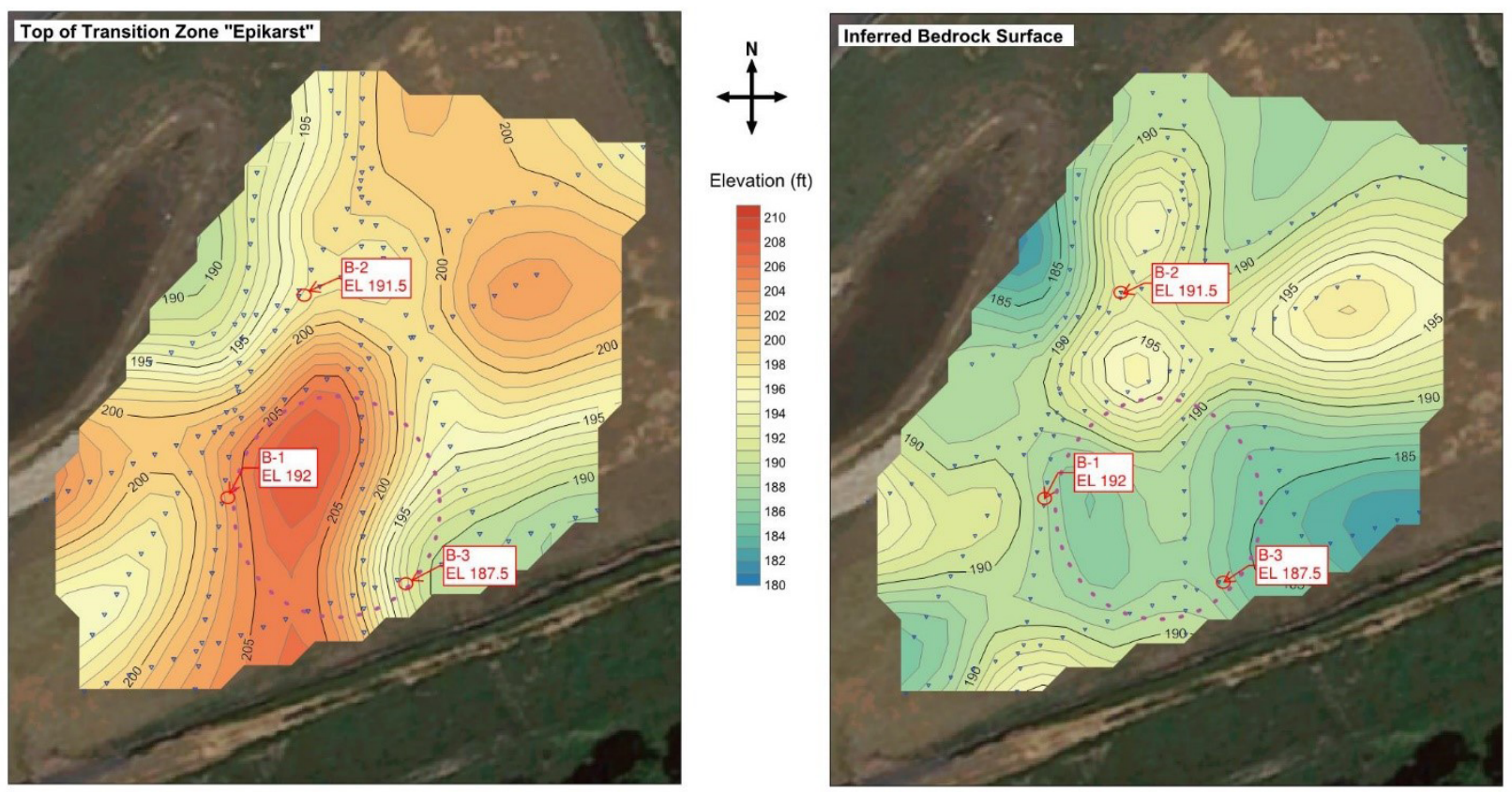

Figure 6. Seismic Refraction Results: (left) Top of Epikarst (1400 mps/4500 fps); (right) top of inferred rock. Top of rock elevations encountered in borings are shown. Red dotted circle depicts the area of sinkholes and dotted gray lines represent the geophysical survey lines. 


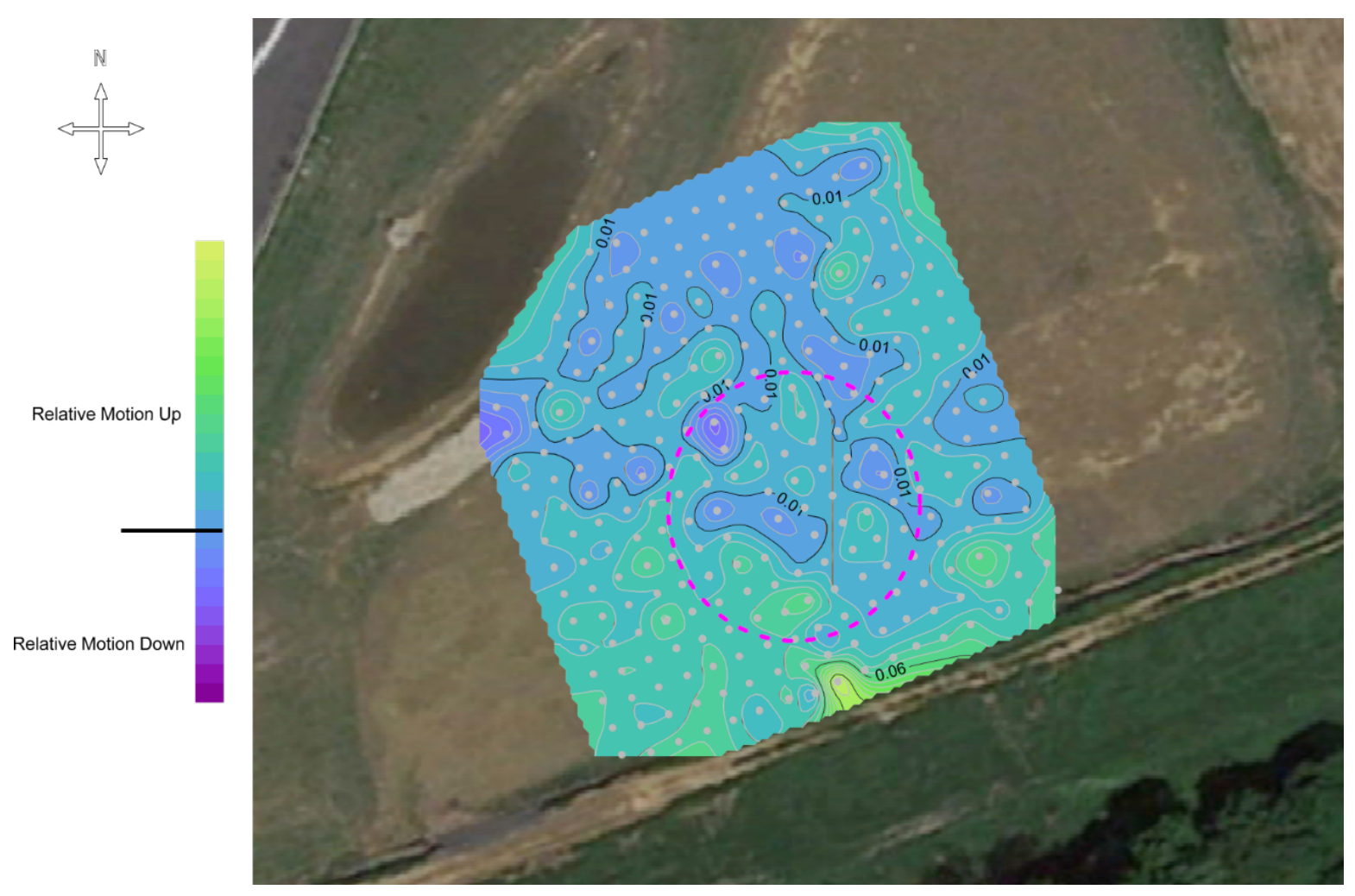

Figure 7. Spontaneous Potential Survey Results. Circle depicts area of sinkholes. Line indicates location of test trench and gray dots indicate measurement locations.

all trend was similar, the orientation and depth of rock, especially in the deeper areas was not in good agreement. One test trench was excavated along the line of a seismic refraction profile line for comparison purposes. The profile encountered in the test excavation is over-laid on the seismic refraction profile is illustrated in Figure 8. The profile clearly indicates the inconsistency, but it should be noted that the inferred top of epikarst from the geophysics is in fairly good agreement with the highest rock encountered in the test excavation. Similarly, the top of sound rock inferred from the seismic refraction agrees pretty well with the deepest rock encountered in the test excavation.

It should be noted that the rock surface varies in three dimensions, and off-line pinnacles affect the measured seismic velocities. Since seismic signals travel all around solution features and through the soil that fills them, there is an averaging affect that arises from seismic refraction surveys.

The spontaneous potential patterns of infiltration zones matched the pattern of sinkholes and agreed reasonably

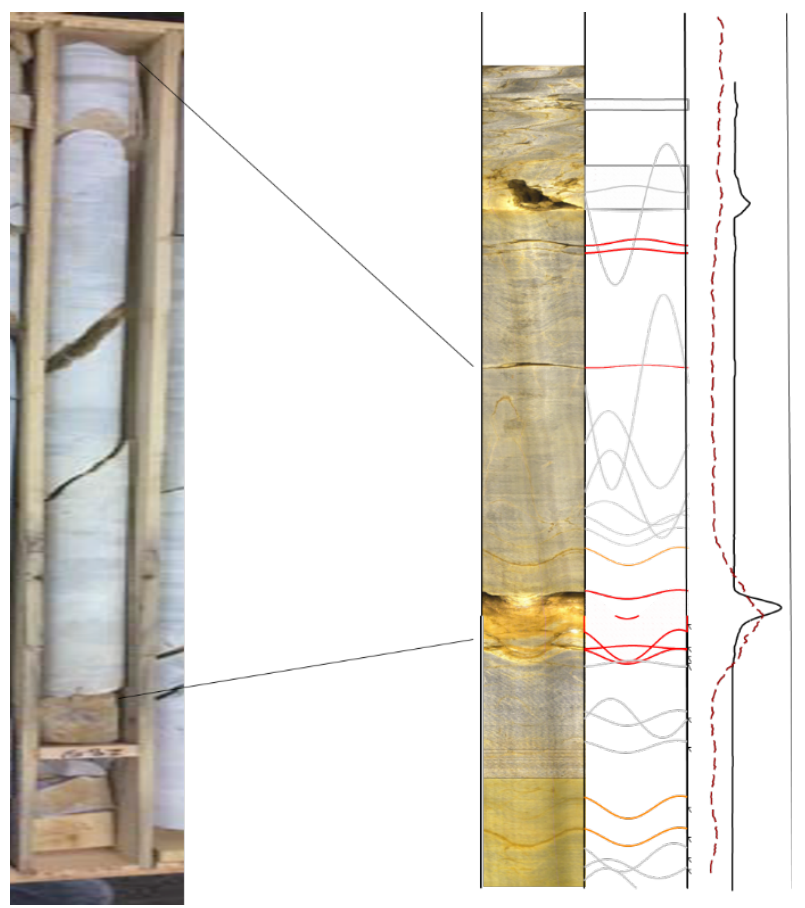

Figure 8. Rock Core C-5 and Televiewer well with the features identified. While there is not a 
one-to-one agreement in all cases, the spontaneous potential test revealed a pattern of behavior that mimicked the sinkhole occurrence at the site.

\section{Discussion}

The difference in the results indicated by the methods is affected by a number of things including groundwater, rock, surface features, etc. Given that groundwater was deep below the top of rock within the site, the surface electromagnetic methods (TC and CCR) were likely unable to resolve the subsurface features due to insufficient contrast, between the dry soils, voids, and sound rock, which would all have displayed relatively high resistivity.

TC generally requires multiple coil spacings to obtain vertical sounding information that would depict the variable depth to top of sound rock (USACE, 1995). Also, anthropogenic features (access roadway, fences, etc.) clearly displayed much higher contrast making it difficult to resolve subtler variation in the subsurface. Had groundwater levels been nearer the surface, the electrical contrast between saturated soil and intact bedrock would likely have resulted in improved results.

The seismic refraction was better able to discern the higher contrast in stiffness between the sound rock and the soils, in light of the deep ground water surface. The relatively low density soils have much lower seismic wave velocity than the sound bedrock. While the method was able to identify the general bedrock topology, it was unable to resolve the full depth of individual solution troughs due to averaging of the wave velocities crossing through pinnacles and soil. While individual pinnacle and trough features were not well defined, the method did, however, quite reasonably depict the upper and lower bounds of the epikarstic zone. The spontaneous potential test did identify active seepage areas that agreed well with the locations of features that had already developed, but also areas where features had, as yet, revealed no surface expression. The increased seepage within the basin induced by water infiltration in the active basin post-construction enhanced the results from the SP survey. While, the groundwater dynamics would have been reduced in the open field prior to the development of the basin, it is highly probable that the most active infiltration areas would still have been detected. On an interesting note, new sinkholes opened some months after the repair of the initial sinkholes at this site at locations predominantly in the areas indicated to have relative downward seepage by the spontaneous potential survey.

There is little doubt that the most accurate methods were excavation and televiewer in cored holes. However, test excavation is highly disruptive and would require extensive soil removal and replacement unless, locations can be selected to depict the essential features and borings are limited to a small diameter at a discrete location and cannot depict the full variability of the rock surface. Accordingly, it is clear that the most effective approach is to use appropriate geophysics to focus the more disruptive test excavations and improve chances for boreholes to intersect features of interest.

\section{Conclusions}

The only way to fully identify all covered karst features would be stripping off all of the overburden to expose the top of rock. This is not a practical solution and it is necessary to characterize the variability of the subsur-

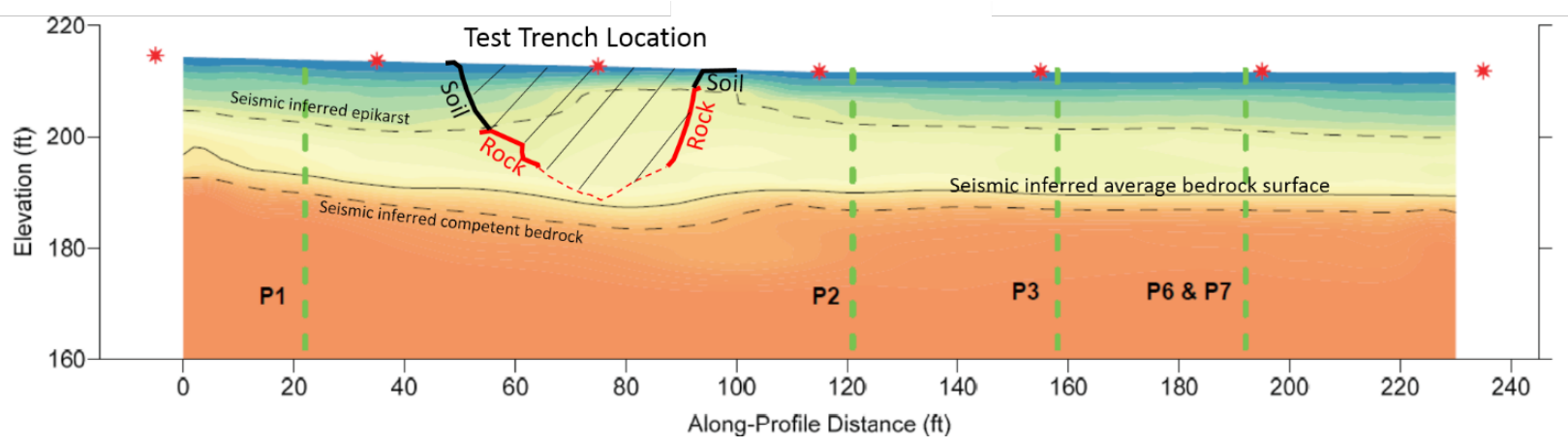

Figure 9. Test Pit Overlay on Seismic Refraction Profile. Dashed line indicates rock surface exposed during sinkhole remediation subsequent to the test excavation. 
face in order to assess the risk for development of a site. Surface geophysical methods can provide useful information helpful to the evaluation of karst sites. However, all surface methods have limitations and have reduced resolution with depth. Karst sites are especially challenging and impose many limitations on the interpretation of geophysical methods.

The purpose of this paper is not to prescribe any specific approach, but to compare the results of several of the low-cost surface methods used at this site. It should be noted that ground penetrating radar (GPR) was not considered appropriate for this site due to the clay content of the soils that typically limits the depth of resolution to three feet or less in this area.

Regarding the methods used:

- Terrain conductivity and CCR were unable to depict the covered karst conditions at this site, likely due to a lack of electrical contrast at depth due, in part to deep groundwater levels and the absence of sounding data in highly variable conditions.

- Seismic refraction provided an improved picture of subsurface variations but was unable to depict abrupt changes in the bedrock surface reflective of solution features at depth.

- A limited number of borings confirmed top of rock indicated by the seismic refraction at most locations within a few feet at a few locations. It is clear that additional borings would have changed the interpretation of conditions. It is important that sufficient borings are used to depict the full range of the depths and conditions expected.

- Coring of the rock provided some evidence of dissolution, but no clear indication of voids. Televiewer survey of the cored hole provided high resolution of solution features and voids within the rock at the borehole locations. The televiewer is useful to identify and evaluate the nature of karst openings, such as whether they are open or filled.

- Test excavations provide the best overall image of the subsurface conditions but were highly disruptive and not practical for large scale site assessment. Test excavations are useful for ground truthing where site conditions permit their use.

- Spontaneous potential provided a very low cost picture of infiltration zones that revealed subsurface variation differently than did the other methods.
- Taking the combination of seismic refraction and spontaneous potential, together with ground truthing test excavation, provides the best overall characterization of the site variability in the rock surface across the site.

This study indicates the importance of understanding site conditions prior to selecting and relying on a single geophysical method (e.g. the presence of clay, groundwater levels, etc). It also illustrates the value of using multiple methods to develop an improved characterization of site conditions. Given its low cost and the direct correlation of downward seepage gradients to subsurface karst features, spontaneous potential is considered a good low cost first level survey that could be incorporated into initial surveys where conditions are suitable. While EM methods are low cost, and often the go-to method for initial surveys, an evaluation of anticipated electrical contrast and consideration of expected groundwater levels is appropriate before performing terrain conductivity for sites like this.

\section{References}

ASTM D6429-99(2011)e1, Standard Guide for Selecting Surface Geophysical Methods, ASTM International, West Conshohocken, PA, 2011, www.astm.org

Carmichael, Robert S. Practical Handbook of Physical Properties of Rocks and Minerals. Boca Raton, Fla.: CRC Press, 1989.

USACE EM 1110-1-1802 Geophysical Exploration For Engineering and Environmental Investigations, US Army Corps of Engineers, 31 August 1995 $208 p$.

Wightman WE, Jalinoos F, Sirles P, and Hanna K. Application of Geophysical Methods to Highway Related Problems. Federal Highway Administration, FHWA Contract DTFH6802-P-00083, Publication FHWA-IF-04-021, 2003 $742 \mathrm{p}$. 